\title{
Is Immunomodulation a Principal Mechanism Underlying How Cell-Based Therapies Enhance Stroke Recovery?
}

\author{
Nikunj Satani ${ }^{1}$ (D) $\cdot$ Sean I. Savitz ${ }^{1}$
}

Published online: 2 August 2016

(C) The American Society for Experimental NeuroTherapeutics, Inc. 2016

\begin{abstract}
Inflammation within the brain and in peripheral tissues contributes to brain injury following ischemic stroke. Therapeutic modulation of the inflammatory response has been actively pursued as a novel stroke treatment approach for decades, without success. In recent years, extensive studies support the high potential for cell-based therapies to become a new treatment modality for stroke and other neurological disorders. In this review, we explore different types of cellular therapies and discuss how they modulate central and peripheral inflammatory processes after stroke. Apart from identifying potential targets for cell therapy, we also discuss paracrine and immunomodulatory mechanisms of cell therapy.
\end{abstract}

Keywords Stroke · Inflammation · Immune response · Cell-based therapy $\cdot$ Microglia $\cdot$ Spleen

\section{Introduction}

Although there have been significant advances in acute stroke care, the majority of patients with stroke have long-term disability. Cell-based therapies represent a new modality that offers high potential to enhance stroke recovery [1-3]. Many different cell types derived from a variety of tissues, including brain, bone marrow, umbilical cord, and adipose tissue, have advanced from the bench to clinical trials [4]. In this review,

Nikunj Satani

nikunj.b.satani@uth.tmc.edu

1 Stroke Program, McGovern Medical School, UTHealth, Houston, TX, USA we discuss the different types of cell therapies that have been studied in animal stroke models and taken forward to clinical studies. Modulation of the immune responses after stroke both within the brain and peripheral tissues is likely an important mechanism underlying how many types of cellular therapies enhance stroke recovery. We review some of the pivotal studies that support an immunomodulatory effect of cell-based therapies in animal stroke models.

\section{Central and Peripheral Mechanisms of Inflammation}

We begin by discussing those aspects of the inflammatory response after stroke that are affected by cell-based therapies. The brisk inflammatory response that begins immediately after stroke can broadly be classified as central or peripheral, depending on whether immune responses originate within the brain or peripheral tissues (Fig. 1). In the brain, resident microglia become activated and migrate to injured areas. Depending on the phenotype they assume, microglia either release proinflammatory cytokines (M1 phenotype polarization) or they can release neurotrophic factors preventing neuronal death and aiding in brain repair (M2 phenotype polarization) [5]. Loane and colleagues [6, 7] showed that microglia in brain can even be chronically activated following brain injury. In parallel to events within the brain, lymphocytes, neutrophils, and monocytes traffic to the brain from the periphery and contribute to further neuronal damage. The spleen is a principal reservoir that reduces in size after stroke, releasing inflammatory cells and cytokines into the circulation [8-15]. In addition, the bone marrow mobilizes a subpopulation of multipotent stem cells into the peripheral blood following stroke, which is then directed towards the brain, as well as peripheral organs such as the spleen [16]. 
Fig. 1 Inflammatory cascade following stroke showing central and peripheral mechanisms. In brain, resident microglia are activated predominantly towards the proinflammatory M1 phenotype. Spleen contracts, releasing inflammatory cells and cytokines. Collectively, they contribute in worsening stroke size

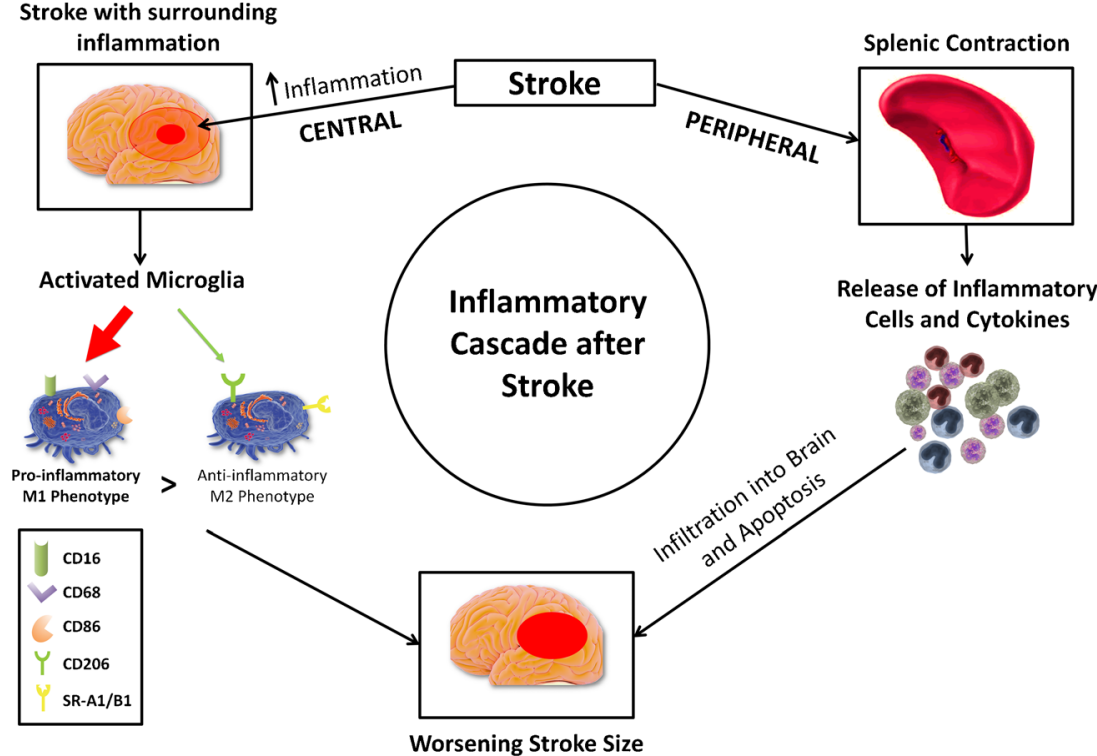

\section{A Brief Review of Cellular Therapies Under Active Investigation}

Different types of cell-based therapies have been studied for years and even decades in animal models of stroke. Included in the following subsections are specific examples of cell therapies that have been extensively studied in animal models and taken forward to clinical trials.

\section{Bone Marrow}

As early as the 1980s, autologous bone marrow injection was used to stimulate healing in tibial fractures, suggesting the reparative effects of marrow cells in large bone defects [17, 18]. Over the last 2 decades, marrow cells have been extensively studied for a range of medical disorders beyond their established uses for transplantation in oncology.

\section{Bone Marrow Stromal Cells}

Marrow stromal cells (MSCs) represent a very small population of the bone marrow which adhere to tissue culture plates making them relatively easy to isolate but need to be grown and passaged in cell culture. MSCs have been shown to exert profound immunomodulatory properties and have gained approval as a treatment in certain countries for graft versus host disease. Several meta-analyses have consistently demonstrated their treatment effects in various animal models of stroke [19-24]. In fact, MSCs are likely the most widely studied type of cell therapy in the preclinical stroke literature [1-3].

\section{Multipotent Adult Progenitor Cells}

The bone marrow also contains another subpopulation of primitive progenitor adherent cells called multipotent adult progenitor cells (MAPCs). They have gene expression and population doubling times distinct from MSCs and have also been found to exert immunomodulatory effects and improve outcome in stroke animal models [20].

\section{Bone Marrow Mononuclear Cells}

The mononuclear fraction within the bone marrow contains MSCs and other stem cells but principally contain many types of mature cells of various lineages. They do not require growth in cell culture and can be easily isolated from bone marrow within hours thereby making autologous testing much easier than more purified cell types [25]. Our previous studies showed that rats treated with autologous mononuclear cells (MNCs) showed significant reductions in lesion size and neurological deficits up to 28 days after stroke [25]. A recent meta-analysis shows the pooled effect size of MNC treatment in animal stroke models [26].

\section{Human Umbilical Cord Blood Stem Cells}

Umbilical cord blood contains a large number of immature progenitor cells and have been studied extensively in stroke animal models because of their limitless supply and simple collection procedure [27]. Various types of cell populations have been isolated from umbilical cord for applications in stroke. Numerous studies have shown neuroprotective effects of human umbilical cord blood stem cells comparable with that of bone marrow stromal cells [1,28-33]. 


\section{Adipose Tissue-Derived Stromal Cells}

Human adipose tissue is also known to contain pluripotent stromal cells and serves as a well explored alternative to bone marrow and umbilical cells [34-39].

\section{Neural Stem Cells}

Neural stem cells (NSCs) are multipotent and self-renewing cells that can differentiate into a wide array of specialized cells in the nervous system $[40,41]$.

\section{Commonality of Mechanisms: Paracrine Hypothesis}

Over a decade of research indicates that many types of cellbased therapies release biological factors that target key aspects of brain injury and repair, including: 1) stimulation of endogenous neurogenesis and angiogenesis; 2) white matter preservation and reorganization; and 3) reduction in cell death of surviving yet vulnerable tissue around the infarct (Fig. 2). There have been many recent studies that demonstrate the role of these trophic factors in recovery after stroke [42-44]. Indeed, the secretomes of cellular therapies have become an active area of research in the hopes of identifying the factors produced by cell therapies that are critical to their effects. Many cell therapies also release microvesicles such as exosomes, which themselves may penetrate and re-engineer the biological properties of target tissues [45-47].
Commonality of Mechanisms: Immunomodulation

There is also growing evidence and even convergence that the immune response is another important target of how some types of cellular therapies may exert their treatment effects. Some of the first speculations to suggest that exogenous cells change the immune response after acute neurological injury arose when it was found that intravenous delivery of human umbilical cord blood cells reduces the expression of proinflammatory cytokines, as well as $\mathrm{CD} 45 / \mathrm{CD} 11 \mathrm{~b}^{-}$and $\mathrm{CD} 45 / \mathrm{B} 220^{+}$cells in the brain [48]. It was subsequently found that the intravenous delivery of many types of cultured stem cells such as MSCs and MAPCs lead to their trapping in peripheral organs - most notably in the lungs and to a lesser extent in the spleen $[49,50]$. This entrapment of exogenous cells may be important to their immunomodulatory effects [51]. For example, MSCs lodging in the lungs may reprogram alveolar macrophages to release anti-inflammatory cytokines through cell-to-cell contact (Fig. 2) [52]. Increasing evidence suggests that MSCs may modulate the immune response after stroke. For example, Yoo et al. [53] found that transforming growth factor (TGF)- $\beta$ secreted by MSCs play a key role in suppressing the immune responses in a rat stroke model [53]. Similarly, as described below, cells entrapped in the spleen could modify splenocytes to exert anti-inflammatory properties by producing interleukin (IL)-4 and IL-10 (Fig. 2) $[51,52]$. The systemic administration of autologous bone marrow mononuclear cells has also been found to reduce the levels of proinflammatory molecules, while increasing antiinflammatory cytokines within the brain and blood [54, 55]. Depending on the delivery route and temporal course of ischemic injury, some types of cell therapies may either
Fig. 2 Cell therapy and its multitarget immunomodulatory function. In brain, cell therapy causes a phenotype shift of resident microglia towards an anti-inflammatory M2 phenotype. Entrapment in lungs reprograms alveolar macrophages, while in spleen they aid in release of antiinflammatory factors, such as interleukin (IL)-4 and IL-10. Release of various trophic factors ensures increased neurogenesis and angiogenesis while decreasing apoptosis of neurons. Collectively, cell therapy reduces post-stroke inflammation and limits stroke expansion

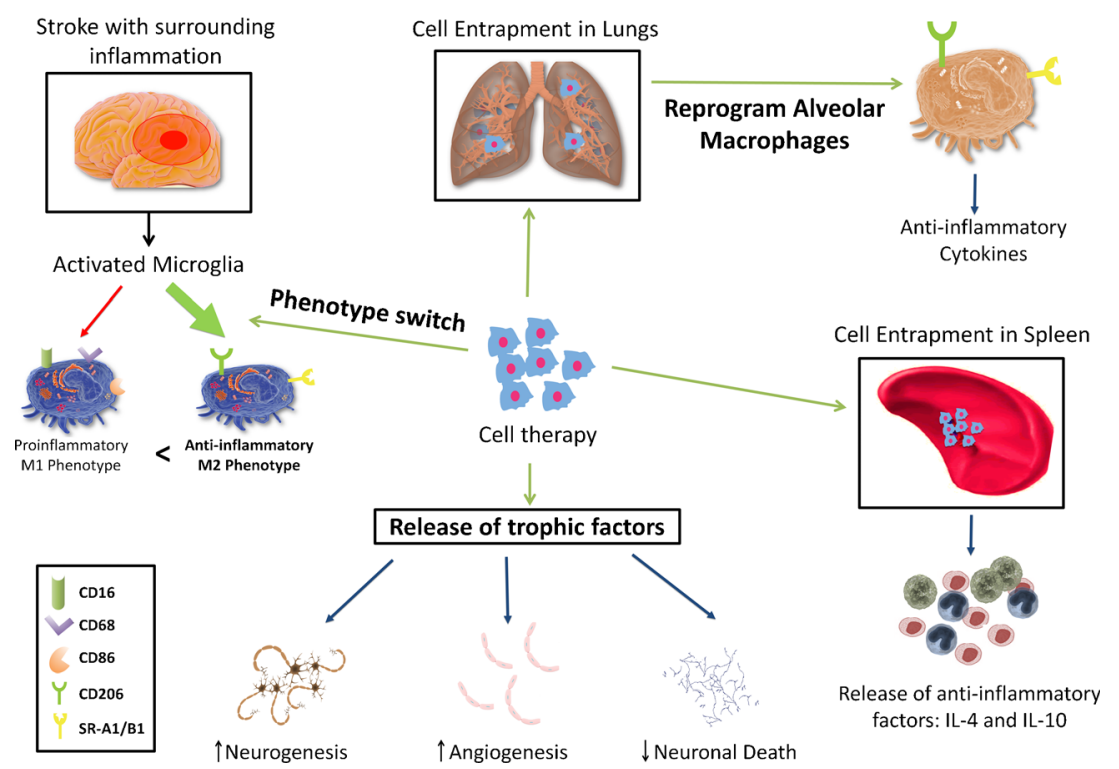


modify immune cell trafficking to the brain, immune cell activation within the brain, or both [28].

It is, however, unknown whether the proregenerative environment created by cell therapy is the direct result of transplanted cells themselves, because of their immune cell activation or some other paracrine mechanisms. A very interesting hypothesis termed "The Dying Stem Cell Hypothesis" provides a different perspective on how cell therapy could exert immunomodulatory effects [56]. According to this hypothesis, at least a part of transplanted cells die either in circulation or after entrapment in the lungs or spleen. Phagocytosis of these apoptotic cells could act as a trigger for release of various anti-inflammatory cytokines [57-59]. It is quite possible that these different mechanisms synergize to create a favorable immunomodulation, which is why further research needs to be focused on finding the exact mechanisms behind how cell therapy enhances recovery through their effects on immune responses.

\section{Targeting the Spleen as a Therapeutic Strategy}

In addition to lungs, the spleen has become an important ]focus to understand how entrapment of certain types of cell therapies modulates the immune response after stroke. Vendrame et al. [31] reported more than 10 years ago that the intravenous administration of umbilical cord cells leads to their migration to the spleen where they restore splenic mass and $T$ cells back to the levels comparable in rats without stroke. These cells also downregulated proinflammatory gene expression and upregulated anti-inflammatory gene expression. Schwarting et al. [60] then found that systemically administered hematopoietic stem cells reduced the expression of proinflammatory cytokines and chemokine receptor gene transcripts. MAPCs also restore spleen mass and stimulate IL-4 and IL-10 production from the spleen in rodents with traumatic brain injury (TBI) [61]; our group has found similar results in a focal stroke model [62]. Even the intravenous delivery of neural stem cells interrupts splenic inflammatory responses in a model of intracerebral hemorrhage [40]. A study by Lee et al. [40] showed that intravenously administered NSCs reduced brain inflammatory infiltration and apoptosis. NSCs caused reduction in levels of both cerebral and splenic inflammatory mediators, most notably tumor necrosis factor- $\alpha$. This study proves that even NSCs act by modulating immune responses in the brain, as well as in the spleen.

Collectively, these studies indicate that intravenous delivery of many types of cell therapies change the splenic response after stroke thereby altering inflammatory cell trafficking to the brain and the overall peripheral immune response $[31,60]$. As a result, secondary injury within the brain is significantly attenuated, which, ultimately, may facilitate brain repair. How interfering with the splenic response can lead to recovery after stroke is poorly understood but may be associated with an upregulation of regulatory $\mathrm{T}$ cells, changes in microglia phenotypes, and repair of the blood-brain barrier (BBB) [63].

There are many studies establishing a role for the spleen in the inflammatory processes following ischemia-perfusion injury of various organs or trauma, with some even showing the importance of splenectomy in reducing the proinflammatory response $[13,64,65]$. As splenectomy is not feasible in patients with stroke, a novel method such as controlling poststroke inflammatory response by enhancing the $\mathrm{CD} 25^{\text {bright }}$ subpopulation of regulatory $\mathrm{T}$ cells could prove useful [66]. However, cell therapy may still have the best proregenerative potential because of its relatively broader immunomodulatory effect.

\section{Targeting Microglia as a Therapeutic Strategy}

In the brain, polarization of microglia towards M1 or M2 phenotypes appears to be a key step driving the inflammatory response and resulting injury in the brain after stroke. This activation occurs even before the inflammatory cells begin to infiltrate the brain parenchyma [67]. If we could use the mediators that drive this polarization as therapeutic targets, we could aim to convert activated microglia towards M2 phenotypes known to be neuroprotective. Utilizing this knowledge of microglial phenotypes, a therapeutic strategy could be devised whereby we can 1) drive the polarization of microglia towards an M2 phenotype after stroke; 2) inhibit M1 microglia from releasing proinflammatory factors; or 3) pharmacologically inhibit factors released by M1 microglia or augment those released by M2 microglia. There have been a number of studies that demonstrate the beneficial neuroprotective and neuroreparative effects of M2 switching [68-71]. These studies have focused on the importance of various M2 markers such as IL-4 [72, 73], IL-10 [72, 74, 75], IL-1RA [76], TGF- $\beta$ [77, 78], CD206 [72, 79], arginase $1[79,80]$, granulocyte macrophage colony-stimulating factor [72], insulin-like growth factor 1 [81, 82], and peroxisome proliferator-activated receptor- $\gamma[70,71,83]$. Even though our understanding of the role of these individual factors have become more insightful, it is very difficult to achieve beneficial neuroprotective effects by modulating just one of these factors. It is more likely that a complex interaction between these factors is responsible for deciding the microglial phenotype.

One major advantage that cell therapy provides is that they do not have one target. They may modulate many aspects of the microglial activation process from M1 to M2 (Fig. 2). For example, Ohtaki et al. [84] found that intracerebral injection of MSCs leads to activation of M2 neuroprotective microglia in a model of global cerebral ischemia. Zanier et al. [85] then 
found in a TBI model that direct injection of MSCs also induces M2 proregenerative traits made evident by downregulation of nitric oxide synthase and upregulation of Ym1, arginase-1, and CD206 mRNA [85]. Another similar study conducted by Hegyi et al. [86] found that MSCs caused polarization of microglia towards a phenotype overexpressing arginase-1, CD86, CD206, IL-10, and prostaglandin E2, and underexpressing tumor necrosis factor- $\alpha$. This unique polarization could attenuate inflammation and enhance brain repair [86]. As some stem cells have the potential to drive microglia towards M1 and M2 phenotypes, depending on the trophic factors released by them, the approach of using stem cells for M1 to M2 polarization can be made even more specific by supplementing them with drugs, for example ones that involve peroxisome proliferator-activated receptor- $\gamma$ activation [87-92]. Still yet another approach for some types of cell therapies is selectively pruning the proinflammatory microglia populations; for example, bone marrow MNCs have been found to promote apoptosis of M1 microglia in a TBI model [93]. Future studies are needed to decipher the mechanisms how cell therapies directly or indirectly (e.g., through the spleen) change the microglial population in the brain.

An important variable supported by many studies is the optimal timing of cell therapy to yield maximum therapeutic effect. Evidence shows that exogenous cells administered shortly after stroke are exposed to lesser hostile environments and are able to exert better neuroprotective effects as compared with longer time windows after stroke [94-96]. NSCs transplanted at $48 \mathrm{~h}$ showed better survival than those transplanted at 1 to 2 weeks, because of an increased exposure to well-established inflammatory milieu in latter group [95]. Pösel et al. [94] showed significant functional improvement in rat stroke models treated with monotherapy of granulocyte colony-stimulating factor (G-CSF), as well as combination therapy of G-CSF and bone marrow MNCs at $6 \mathrm{~h}$ poststroke. When bone marrow MNCs were given at $48 \mathrm{~h}$, the beneficial effect of G-CSF therapy was completely abolished [94]. These studies show that timing of cell therapy can play a vital role in functional outcome.

Another viable approach to increase the potency of implanted stem cells is by creating stem cells overexpressing secretory molecules, which could modulate microglial/ macrophage functions. Along the same lines, galectin-1 overexpressing neural stem cells when transplanted in stroke, were shown to reduce infarct volume, improve sensorimotor and cognitive functions, and ameliorated white matter injury. In addition, they modulated microglial function by reducing the secretion of proinflammatory cytokines in response to LPS stimulation and by enhancing the secretion of anti-inflammatory cytokines like IL-10 and TGF- $\beta$. This study indicates that galectin- 1 aided in the release of molecules, which shifted microglia towards an M2 phenotype [97]. Future studies are important to identify methods to increase the potency of cell therapies to target microglia.

\section{Preservation of BBB Integrity}

BBB integrity plays a critical role in maintaining brain homeostasis and its disruption is among the initial steps in the evolving course of injury in stroke. Another anti-inflammatory mechanism for cell therapies may be a direct effect on the flow of inflammatory mediators entering the brain after stroke. Several studies have found that cell therapies reduce BBB disruption in models of acute neurological injury $[98,99]$. Multiple pathways may be involved. Menge et al. [100] found that MSCs release tissue inhibitor of metalloproteinase 3 , which leads to the preservation of adherens junctions and tight junctions of cerebral endothelial cells. Others have found that MSCs inhibit the upregulation of aquaporin-4 [101].

\section{Conclusion}

As an advantage over pharmacological agents, cell therapies very likely engage multiple biological targets. Their immunomodulatory effects appear more selective compared with other approaches that broadly suppress the immune response to injury. Selective modulation may promote a more proregenerative environment. In view of the central and peripheral immunomodulatory effects of various cell therapies, several key questions arise for future study. There is a need to identify what the key immune targets are, how long after injury these targets are available or modifiable, and whether immune targets may even be appropriate for the application of cell therapies for chronic stroke.

Required Author Forms Disclosure forms provided by the authors are available with the online version of this article.

\section{References}

1. Chen J, Sanberg PR, Li Y, et al. Intravenous administration of human umbilical cord blood reduces behavioral deficits after stroke in rats. Stroke 2001;32:2682-2688.

2. Li Y, Chen J, Wang L, Lu M, Chopp M. Treatment of stroke in rat with intracarotid administration of marrow stromal cells. Neurology 2001;56:1666-1672.

3. Chen J, Li Y, Wang L, et al. Therapeutic benefit of intravenous administration of bone marrow stromal cells after cerebral ischemia in rats. Stroke 2001;32:1005-1011.

4. Savitz SI, Dinsmore JH, Wechsler LR, Rosenbaum DM, Caplan LR. Cell therapy for stroke. NeuroRx 2004;1:406-414. 
5. Hu X, Leak RK, Shi Y, et al. Microglial and macrophage polarization-new prospects for brain repair. Nat Rev Neurol 2015;11:56-64.

6. Loane DJ, Kumar A, Stoica BA, Cabatbat R, Faden AI. Progressive neurodegeneration after experimental brain trauma: association with chronic microglial activation. J Neuropathol Exp Neurol 2014;73:14-29.

7. Faden AI, Wu J, Stoica BA, Loane DJ. Progressive inflammationmediated neurodegeneration after traumatic brain or spinal cord injury. Br J Pharmacol 2016;173:681-691.

8. Vahidy FS, Parsha KN, Rahbar MH, et al. Acute splenic responses in patients with ischemic stroke and intracerebral hemorrhage. $\mathrm{J}$ Cereb Blood Flow Metab 2016;36:1012-1021.

9. Liu ZJ, Chen C, Li FW, et al. Splenic responses in ischemic stroke: new insights into stroke pathology. CNS Neurosci Ther 2015;21: 320-326.

10. Pennypacker KR, Offner H. The role of the spleen in ischemic stroke. J Cereb Blood Flow Metab 2015;35:186-187.

11. Offner H, Subramanian S, Parker SM, et al. Splenic atrophy in experimental stroke is accompanied by increased regulatory $\mathrm{T}$ cells and circulating macrophages. J Immunol 2006;176:6523-6531.

12. Swirski FK, Nahrendorf M, Etzrodt M, et al. Identification of splenic reservoir monocytes and their deployment to inflammatory sites. Science 2009;325:612-616.

13. Ajmo CT, Jr., Vernon DO, Collier L, et al. The spleen contributes to stroke-induced neurodegeneration. J Neurosci Res 2008;86: 2227-2234.

14. Courties G, Moskowitz MA, Nahrendorf M. The innate immune system after ischemic injury: lessons to be learned from the heart and brain. JAMA Neurol 2014;71:233-236.

15. Dutta P, Courties G, Wei Y, et al. Myocardial infarction accelerates atherosclerosis. Nature 2012;487:325-329.

16. Kucia M, Zhang YP, Reca R, et al. Cells enriched in markers of neural tissue-committed stem cells reside in the bone marrow and are mobilized into the peripheral blood following stroke. Leukemia 2006;20:18-28.

17. Connolly JF, Guse R, Tiedeman J, Dehne R. Autologous marrow injection as a substitute for operative grafting of tibial nonunions. Clin Orthop Relat Res 1991:259-270.

18. Connolly JF, Guse R, Tiedeman J, Dehne R. Autologous marrow injection for delayed unions of the tibia: a preliminary report. J Orthop Trauma 1989;3:276-282.

19. Lees JS, Sena ES, Egan KJ, et al. Stem cell-based therapy for experimental stroke: a systematic review and meta-analysis. Int J Stroke 2012;7:582-588.

20. Mora-Lee S, Sirerol-Piquer MS, Gutierrez-Perez M, et al. Therapeutic effects of hMAPC and hMSC transplantation after stroke in mice. PLOS ONE 2012;7:e43683.

21. Honmou O, Onodera R, Sasaki M, Waxman SG, Kocsis JD. Mesenchymal stem cells: therapeutic outlook for stroke. Trends Mol Med 2012;18:292-297.

22. Dharmasaroja P. Bone marrow-derived mesenchymal stem cells for the treatment of ischemic stroke. J Clin Neurosci 2009;16:12-20.

23. Chen J, Zhang ZG, Li Y, et al. Intravenous administration of human bone marrow stromal cells induces angiogenesis in the ischemic boundary zone after stroke in rats. Circ Res 2003;92: 692-699.

24. Li Y, Chen J, Chen XG, et al. Human marrow stromal cell therapy for stroke in rat: neurotrophins and functional recovery. Neurology 2002;59:514-523.

25. Yang B, Strong R, Sharma S, et al. Therapeutic time window and dose response of autologous bone marrow mononuclear cells for ischemic stroke. J Neurosci Res 2011;89:833-839.
26. Vahidy FS, Rahbar MH, Zhu H, Rowan PJ, Bambhroliya AB, Savitz SI. Systematic review and meta-analysis of bone marrowderived mononuclear cells in animal models of ischemic stroke. Stroke 2016;47:1632-1639.

27. Moise KJ, Jr. Umbilical cord stem cells. Obstet Gynecol 2005;106:1393-1407.

28. Stone LL, Xiao F, Rotshafer J, et al. Amelioration of ischemic brain injury in rats with human umbilical cord blood stem cells: mechanisms of action. Cell Transplant 2016 Mar 18 [Epub ahead of print].

29. Kim K, Park HW, Moon HE, et al. The effect of human umbilical cord blood-derived mesenchymal stem cells in a collagenaseinduced intracerebral hemorrhage rat model. Exp Neurobiol 2015;24:146-155.

30. Womble TA, Green S, Shahaduzzaman M, et al. Monocytes are essential for the neuroprotective effect of human cord blood cells following middle cerebral artery occlusion in rat. Mol Cell Neurosci 2014;59:76-84.

31. Vendrame M, Gemma C, Pennypacker KR, et al. Cord blood rescues stroke-induced changes in splenocyte phenotype and function. Exp Neurol 2006;199:191-200.

32. Vendrame M, Cassady J, Newcomb J, et al. Infusion of human umbilical cord blood cells in a rat model of stroke dosedependently rescues behavioral deficits and reduces infarct volume. Stroke 2004:35:2390-2395.

33. Yan T, Venkat $\mathrm{P}$, Ye X, et al. HUCBCs increase angiopoietin 1 and induce neurorestorative effects after stroke in T1DM rats. CNS Neurosci Ther 2014;20:935-944.

34. Wang J, Li G. [Adipose-derived stem cell transplantation inhibits the expression of Nogo-A in the perilesional cortex of rats with focal cerebral ischemia]. Xi Bao Yu Fen Zi Mian Yi Xue Za Zhi 2016;32:39-43.

35. Zhou F, Gao S, Wang L, et al. Human adipose-derived stem cells partially rescue the stroke syndromes by promoting spatial learning and memory in mouse middle cerebral artery occlusion model. Stem Cell Res Ther 2015;6:92.

36. Jiang W, Liang G, Li X, et al. Intracarotid transplantation of autologous adipose-derived mesenchymal stem cells significantly improves neurological deficits in rats after MCAo. J Mater Sci Mater Med 2014;25:1357-1366.

37. Egashira Y, Sugitani S, Suzuki Y, et al. The conditioned medium of murine and human adipose-derived stem cells exerts neuroprotective effects against experimental stroke model. Brain Res 2012;1461:87-95.

38. Lee TH, Yoon JG. Intracerebral transplantation of human adipose tissue stromal cells after middle cerebral artery occlusion in rats. J Clin Neurosci 2008;15:907-912.

39. Kang SK, Lee DH, Bae YC, Kim HK, Baik SY, Jung JS. Improvement of neurological deficits by intracerebral transplantation of human adipose tissue-derived stromal cells after cerebral ischemia in rats. Exp Neurol 2003;183:355-366.

40. Lee ST, Chu K, Jung KH, et al. Anti-inflammatory mechanism of intravascular neural stem cell transplantation in haemorrhagic stroke. Brain 2008;131:616-629.

41. Ourednik J, Ourednik V, Lynch WP, Schachner M, Snyder EY. Neural stem cells display an inherent mechanism for rescuing dysfunctional neurons. Nat Biotechnol 2002;20:1103-1110.

42. Gu Y, He M, Zhou X, et al. Endogenous IL-6 of mesenchymal stem cell improves behavioral outcome of hypoxic-ischemic brain damage neonatal rats by supressing apoptosis in astrocyte. Sci Rep 2016;6:18587.

43. Bang OY, Jin KS, Hwang MN, et al. The effect of CXCR4 overexpression on mesenchymal stem cell transplantation in ischemic stroke. Cell Med 2012;4:65-76.

44. Ay I, Sugimori H, Finklestein SP. Intravenous basic fibroblast growth factor (bFGF) decreases DNA fragmentation and prevents 
downregulation of $\mathrm{Bcl}-2$ expression in the ischemic brain following middle cerebral artery occlusion in rats. Brain Res Mol Brain Res 2001;87:71-80.

45. Xin H, Li Y, Chopp M. Exosomes/miRNAs as mediating cellbased therapy of stroke. Front Cell Neurosci 2014;8:377.

46. Yeo RW, Lai RC, Zhang B, et al. Mesenchymal stem cell: an efficient mass producer of exosomes for drug delivery. Adv Drug Deliv Rev 2013;65:336-341.

47. Chen TS, Arslan F, Yin Y, et al. Enabling a robust scalable manufacturing process for therapeutic exosomes through oncogenic immortalization of human ESC-derived MSCs. J Transl Med 2011;9:47.

48. Vendrame M, Gemma C, de Mesquita D, et al. Anti-inflammatory effects of human cord blood cells in a rat model of stroke. Stem Cells Dev 2005;14:595-604.

49. Fischer UM, Harting MT, Jimenez F, et al. Pulmonary passage is a major obstacle for intravenous stem cell delivery: the pulmonary first-pass effect. Stem Cells Develop 2009;18:683-692.

50. Barbash IM, Chouraqui P, Baron J, et al. Systemic delivery of bone marrow-derived mesenchymal stem cells to the infarcted myocardium: feasibility, cell migration, and body distribution. Circulation 2003;108:863-868.

51. Walker PA, Shah SK, Jimenez F, Aroom KR, Harting MT, Cox CS, Jr. Bone marrow-derived stromal cell therapy for traumatic brain injury is neuroprotective via stimulation of non-neurologic organ systems. Surgery 2012;152:790-793.

52. Nemeth K, Leelahavanichkul A, Yuen PS, et al. Bone marrow stromal cells attenuate sepsis via prostaglandin E(2)-dependent reprogramming of host macrophages to increase their interleukin-10 production. Nat Med 2009;15:42-49.

53. Yoo SW, Chang DY, Lee HS, et al. Immune following suppression mesenchymal stem cell transplantation in the ischemic brain is mediated by TGF-beta. Neurobiol Dis 2013;58:249-257.

54. Brenneman M, Sharma S, Harting M, et al. Autologous bone marrow mononuclear cells enhance recovery after acute ischemic stroke in young and middle-aged rats. J Cereb Blood Flow Metab 2010;30:140-149.

55. Yang B, Migliati E, Parsha K, et al. Intra-arterial delivery is not superior to intravenous delivery of autologous bone marrow mononuclear cells in acute ischemic stroke. Stroke 2013;44: 3463-3472.

56. Thum T, Bauersachs J, Poole-Wilson PA, Volk HD, Anker SD. The dying stem cell hypothesis: immune modulation as a novel mechanism for progenitor cell therapy in cardiac muscle. J Am Coll Cardiol 2005;46:1799-1802.

57. Bolton AE. Biologic effects and basic science of a novel immunemodulation therapy. Am J Cardiol 2005;95:24C-29C.

58. Maderna P, Godson C. Phagocytosis of apoptotic cells and the resolution of inflammation. Biochim Biophys Acta 2003;1639: 141-151.

59. Voll RE, Herrmann M, Roth EA, Stach C, Kalden JR, Girkontaite I. Immunosuppressive effects of apoptotic cells. Nature 1997;390: 350-351.

60. Schwarting S, Litwak S, Hao W, Bahr M, Weise J, Neumann H. Hematopoietic stem cells reduce postischemic inflammation and ameliorate ischemic brain injury. Stroke 2008;39:2867-2875.

61. Walker PA, Shah SK, Jimenez F, et al. Intravenous multipotent adult progenitor cell therapy for traumatic brain injury: preserving the blood brain barrier via an interaction with splenocytes. Exp Neurol 2010;225:341-352.

62. Yang B, Hamilton J, Strong R, Xi X, Mays R, Savitz S. Human multipotential bone marrow stem cells exert immunomodulatory effects, prevent splenic contraction, and enhance functional reco very in a rodent model of ischemic stroke. Stroke 2011;42:E67.

63. Walker PA, Bedi SS, Shah SK, et al. Intravenous multipotent adult progenitor cell therapy after traumatic brain injury: modulation of the resident microglia population. J Neuroinflammation 2012;9:228.

64. Seifert HA, Leonardo CC, Hall AA, et al. The spleen contributes to stroke induced neurodegeneration through interferon gamma signaling. Metab Brain Dis 2012;27:131-141.

65. Crandall M, Shapiro MB, West MA. Does splenectomy protect against immune-mediated complications in blunt trauma patients? Mol Med 2009;15:263-267.

66. Wang $\mathrm{K}, \mathrm{Gu} \mathrm{J}, \mathrm{Ni} \mathrm{X}$, et al. CD25 signaling regulates the function and stability of peripheral Foxp3+ regulatory T cells derived from the spleen and lymph nodes of mice. Mol Immunol 2016;76:35-40.

67. Gelderblom M, Leypoldt F, Steinbach K, et al. Temporal and spatial dynamics of cerebral immune cell accumulation in stroke. Stroke 2009;40:1849-1857.

68. Herder V, Iskandar CD, Kegler K, et al. Dynamic changes of microglia/macrophage M1 and M2 polarization in Theiler's murine encephalomyelitis. Brain Pathol 2015;25:712-723.

69. Miron VE, Boyd A, Zhao JW, et al. M2 microglia and macrophages drive oligodendrocyte differentiation during CNS remyelination. Nat Neurosci 2013;16:1211-1218.

70. Zhao X, Grotta J, Gonzales N, Aronowski J. Hematoma resolution as a therapeutic target: the role of microglia/macrophages. Stroke 2009;40(3 Suppl.):S92-S94.

71. Zhao X, Sun G, Zhang J, et al. Hematoma resolution as a target for intracerebral hemorrhage treatment: role for peroxisome proliferator-activated receptor gamma in microglia/macrophages. Ann Neurol 2007;61:352-362.

72. Chhor V, Le Charpentier T, Lebon S, et al. Characterization of phenotype markers and neuronotoxic potential of polarised primary microglia in vitro. Brain Behav Immun 2013;32:70-85.

73. Fenn AM, Henry CJ, Huang Y, Dugan A, Godbout JP. Lipopolysaccharide-induced interleukin (IL)-4 receptor-alpha expression and corresponding sensitivity to the M2 promoting effects of IL-4 are impaired in microglia of aged mice. Brain Behav Immun 2012;26:766-777.

74. Crain JM, Nikodemova M, Watters JJ. Microglia express distinct M1 and M2 phenotypic markers in the postnatal and adult central nervous system in male and female mice. J Neurosci Res 2013;91: 1143-1151.

75. La Flamme AC, Kharkrang M, Stone S, Mirmoeini S, Chuluundorj D, Kyle R. Type II-activated murine macrophages produce IL-4. PLOS ONE 2012;7:e46989.

76. Hanisch UK. Functional diversity of microglia-how heterogeneous are they to begin with? Front Cell Neurosci 2013;7:65.

77. Jaguin M, Houlbert N, Fardel O, Lecureur V. Polarization profiles of human M-CSF-generated macrophages and comparison of M1markers in classically activated macrophages from GM-CSF and M-CSF origin. Cell Immunol 2013;281:51-61.

78. David S, Kroner A. Repertoire of microglial and macrophage responses after spinal cord injury. Nat Rev Neurosci 2011;12: 388-399.

79. Hu X, Li P, Guo Y, et al. Microglia/macrophage polarization dynamics reveal novel mechanism of injury expansion after focal cerebral ischemia. Stroke 2012;43:3063-3070.

80. Hirai T, Uchida K, Nakajima H, et al. The prevalence and phenotype of activated microglia/macrophages within the spinal cord of the hyperostotic mouse (twy/twy) changes in response to chronic progressive spinal cord compression: implications for human cervical compressive myelopathy. PLOS ONE 2013;8:e64528.

81. De Magalhaes Filho CD, Kappeler L, Dupont J, et al. Deleting IGF-1 receptor from forebrain neurons confers neuroprotection during stroke and upregulates endocrine somatotropin. J Cereb Blood Flow Metab 2016 Jan 13 [Epub ahead of print].

82. Ebinger $\mathrm{M}$, Ipsen $\mathrm{N}$, Leonards $\mathrm{CO}$, et al. Circulating insulinlike growth factor binding protein-3 predicts one-year 
outcome after ischemic stroke. Exp Clin Endocrinol Diabetes 2015;123:461-465.

83. Pisanu A, Lecca D, Mulas G, et al. Dynamic changes in pro- and anti-inflammatory cytokines in microglia after PPAR-gamma agonist neuroprotective treatment in the MPTPp mouse model of progressive Parkinson's disease. Neurobiol Dis 2014;71:280-291.

84. Ohtaki H, Ylostalo JH, Foraker JE, et al. Stem/progenitor cells from bone marrow decrease neuronal death in global ischemia by modulation of inflammatory/immune responses. Proc Natl Acad Sci U S A 2008;105:14638-14643.

85. Zanier ER, Pischiutta F, Riganti L, et al. Bone marrow mesenchymal stromal cells drive protective M2 microglia polarization after brain trauma. Neurotherapeutics 2014;11:679-695.

86. Hegyi B, Kornyei Z, Ferenczi S, et al. Regulation of mouse microglia activation and effector functions by bone marrowderived mesenchymal stem cells. Stem Cells Develop 2014;23: 2600-2612.

87. Gliem M, Klotz L, van Rooijen N, Hartung HP, Jander S. Hyperglycemia and PPARgamma antagonistically influence macrophage polarization and infarct healing after ischemic stroke. Stroke 2015;46:2935-2942.

88. Wu JS, Tsai HD, Cheung WM, Hsu CY, Lin TN. PPAR-gamma ameliorates neuronal apoptosis and ischemic brain injury via suppressing NF-kappaB-driven p22phox transcription. Mol Neurobiol 2016;53:3626-3645.

89. Chu K, Lee ST, Koo JS, et al. Peroxisome proliferator-activated receptor-gamma-agonist, rosiglitazone, promotes angiogenesis after focal cerebral ischemia. Brain Res 2006;1093:208-218.

90. Certo M, Endo Y, Ohta K, Sakurada S, Bagetta G, Amantea D. Activation of RXR/PPARgamma underlies neuroprotection by bexarotene in ischemic stroke. Pharmacol Res 2015;102:298-307.

91. Lan LF, Zheng L, Yang X, Ji XT, Fan YH, Zeng JS. Peroxisome proliferator-activated receptor-gamma agonist pioglitazone ameliorates white matter lesion and cognitive impairment in hypertensive rats. CNS Neurosci Ther 2015;21:410-416.

92. Yu YL, Chou RH, Shyu WC, et al. Smurf2-mediated degradation of EZH2 enhances neuron differentiation and improves functional recovery after ischaemic stroke. EMBO Mol Med 2013;5:531-547.

93. Bedi SS, Walker PA, Shah SK, et al. Autologous bone marrow mononuclear cells therapy attenuates activated microglial/macrophage response and improves spatial learning after traumatic brain injury. J Trauma Acute Care Surg 2013;75:410-416.

94. Posel C, Scheibe J, Kranz A, et al. Bone marrow cell transplantation time-dependently abolishes efficacy of granulocyte colonystimulating factor after stroke in hypertensive rats. Stroke 2014; 45:2431-2437.

95. Darsalia V, Allison SJ, Cusulin C, et al. Cell number and timing of transplantation determine survival of human neural stem cell grafts in stroke-damaged rat brain. J Cereb Blood Flow Metab 2011;31:235-242.

96. Newcomb JD, Ajmo CT, Jr., Sanberg CD, Sanberg PR, Pennypacker KR, Willing AE. Timing of cord blood treatment after experimental stroke determines therapeutic efficacy. Cell Transplant 2006; 15:213-223.

97. Wang J, Xia J, Zhang F, et al. Galectin-1-secreting neural stem cells elicit long-term neuroprotection against ischemic brain injury. Sci Rep 2015;5:9621.

98. Wang C, Fei Y, Xu C, Zhao Y, Pan Y. Bone marrow mesenchymal stem cells ameliorate neurological deficits and blood-brain barrier dysfunction after intracerebral hemorrhage in spontaneously hypertensive rats. Int J Clin Exp Pathol 2015;8:4715-4724.

99. Chen M, Li X, Zhang X, et al. The inhibitory effect of mesenchymal stem cell on blood-brain barrier disruption following intracerebral hemorrhage in rats: contribution of TSG-6. J Neuroinflammation 2015;12:61.

100. Menge T, Zhao Y, Zhao J, et al. Mesenchymal stem cells regulate blood-brain barrier integrity through TIMP3 release after traumatic brain injury. Sci Transl Med 2012;4:161ra50.

101. Tang G, Liu Y, Zhang Z, et al. Mesenchymal stem cells maintain blood-brain barrier integrity by inhibiting aquaporin-4 upregulation after cerebral ischemia. Stem Cells 2014;32:3150-3162. 